\title{
Optimization of wind speed on dispersion of pollutants using coupled receptor and dispersion model
}

\author{
N ANU, S RANGABHASHIYAM, RAHUL ANTONY \\ and N SELVARAJU*
}

Department of Chemical Engineering, National Institute of Technology Calicut, Kozhikode 673601, Kerala, India

e-mail: selvaraju@nitc.ac.in

MS received 31 December 2014; revised 25 March 2015; accepted 11 April 2015

\begin{abstract}
Air pollutants emission from various source categories can be quantified through mass balance (receptor model) techniques, multivariate data analysis and dispersion model. The composition of particulate matter from various emission points (emission inventory) and the massive analysis of the composition in the collected samples from various locations (receptor) are used to estimate quantitative source contribution through receptor models. In dispersion model, on the other hand the emission rates $\left(\mu \mathrm{g} / \mathrm{m}^{3}\right)$ from various sources together with particle size, stack height, topography, meteorological conditions (temperature, humidity, wind speed and directions, etc.) will affect the pollutant concentration at a point or in a region. The parameters used in dispersion model are not considering in receptor models but have been affecting indirectly as difference concentration at various receptor locations. These differences are attributed and possible erroneous results can be viewed through coupled receptor-dispersion model analysis. The current research work proposed a coupled receptor-dispersion model to reduce the difference between predicted concentrations through optimized wind velocity used in dispersion model. The converged wind velocities for various error percentages $(10 \%, 40 \%, 60 \%$ and $80 \%)$ in receptor concentration have been obtained with corresponding increase in the error. The proposed combined approaches help to reconcile the differences arise when the two models used in an individual mode.
\end{abstract}

Keywords. Receptor model; dispersion model; wind velocity; optimization; coupled model.

\section{Introduction}

The classical approaches of dispersion model (Qian \& Venkatram 2001; Holmes \& Morawska 2006) and receptor model (Harrison et al 1997; Guo et al 2009) have been widely used in the

${ }^{*}$ For correspondence 
area of atmospheric science to predict the extent of pollution. These two approaches have been used independently in the past. Dispersion models are used to predict concentrations at point in the downwind direction by using various meteorological parameters. The various forms of dispersion model have been used to determine concentrations from point sources (Barrett \& Britter 2008), line sources (Held et al 2003; Barrett \& Britter 2009), and area sources (Barrett \& Britter 2009) prevailing in a region. A combined approach of these two models can be seen to refine the results obtained from the individual model prediction (Haupt 2005; Selvaraju \& Pushpavanam 2010). The dispersion of pollutants can be influenced by the meteorological parameters of which wind speed and direction plays major role in convection (Hossain \& Easa 2012).

Different agencies analyzed and compared the effect of the three-dimensional (3D) building geometries in urban wind flow and dispersion models using Lagrangian dispersion models such as Quick Urban and Industrial Complex (QUIC), 3-Dimensional Wind Field (3DWF), and the urban Lagrangian model and Microswift/Spray (MSS). The wind fields and tracer contour patterns were agreed in good with wind speed near the surface mean model biases were less than about $20 \%$ and RMS errors are about 1-2 m/s (Hanna et al 2011). To overcome the implicit restrictions in the Gaussian plume model approximate values can use in puff emission series through varying wind speed (Holmes \& Morawska 2006) The use of observed cross-wind integrated concentrations produces more accurate in identification of source emission that the use of observed point concentrations, but the uncertainty can be high about a factor of two (Hanna et al 1990). The dispersion model's ability has to be checked using ensemble inputs to predict probability distributions measures. The dispersion model has been used with the atmospheric dynamic model by including the variability in the individual wind fields, to generate dosage probabilities (Warner et al 2002). In dispersion the convection diffusion equation taking into account due to turbulence in terms of a dispersion coefficient (Selvaraju \& Pushpavanam 2010). Dust emission was simulated using Lagrangian Dust Model (LDM) and compared the source-receptor to establish the relationships with the simulated dust concentration. The model accuracy and uncertainty were evaluated by Eulerian model and statistical approach (Kim \& Lee 2012).

A comparison between advection-diffusion and Gaussian plume model to predict dispersion in low wind speed can reduce the over estimation of concentration at surface release. The correlation coefficient between predicted and observed concentration has been observed high for numerical model than Gaussian plume model by AERMOD due to the variation in the wind speed and other model parameters (Qian \& Venkatram 2001). A better ground level concentration was observed when the vertical cross wind integrated concentration modelled with lognormal distribution as part of comparison between simplified convective dispersion model and AERMOD to study the pollutant transport in the atmosphere from stack emission (Stull \& Ainslie 2006).

Pollution levels at a point to due to different sources can attribute through receptor modeling techniques such as chemical mass balance (CMB) (Harrison et al 1997; Fraser et al 2003; Begum et al 2004; Chowdhury et al 2007; Guo et al 2009), which can demonstrate the contribution of each source at the receptor location (Pant \& Harrison 2012; Belis et al 2013). The steps in receptor model include analyze the composition of particulate matter and use the source profiles of each source through emission inventory to estimate quantitative source contributions (Larsen \& Baker 2003; Lai et al 2005; Song et al 2006). The chemical mass balance approach needs knowledge of possible sources in a region which can contribute to pollution levels and their source profiles (Tsai \& Chen 2006; Selvaraju et al 2013). Obtaining accurate source profiles along with receptor concentrations is a limitation of this approach (Vinod et al 2001; Holmes \& Morawska 2006; Stone et al 2010). Atmospheric conditions can influence the concentration of the species 
at the receptor location, which is not playing directly in a receptor model. In dispersion modeling pollutant concentrations are estimated together with meteorological conditions and can be used the source contributions results at a point (Receptor). Wind velocity is a parameter in the dispersion equation and which depends on the various atmospheric stability criteria (Seinfeld \& Pandis 2006).

In this study, coupled receptor-dispersion model approach uses the information of emission inventory estimates as well as receptor concentrations to arrive at a more accurate value of wind velocity at a point or in a region. Also there will be a probability of significant differences between the model prediction and experimentally measured velocities. In addition the meteorological conditions measured at a point may not be representative of that prevailing in a region and this can result in erroneous predictions of the contributions of various sources. In the context of using coupled receptor dispersion model, Haupt (2005) proposed an approach based on genetic algorithms to overcome the limitations of the individual approaches and combine their benefits.

\section{Materials and methods}

The dispersion model states that the contribution of $k^{\text {th }}$ source $\left(S_{k}\right)$ to a receptor is the product of an emissions rate, $E_{k}$, and a dispersion factor, $D_{k}$, so that,

$$
S_{k}=D_{k} \cdot \times E_{k}
$$

where $E_{k}$ and $D_{k}$ have non-linear expressions which include the meteorological parameters to calculate the concentration. Based on the geometric form of the emission source, dispersion formulae have been classified as point, line, and area sources models. Dispersion factor for a given source geometry along with known meteorological parameters such as wind speed, direction and atmospheric stability is the goal of air quality meteorology (Henry et al 1984).

The concentration of the pollutants from different sources can be obtained from dispersion model, which represents the source contributions at that point. The contributions can also be estimated via a receptor model from a speciation analysis of samples of particulate matter (PM) collected (Hossain \& Easa 2012). In the current study, chemical mass balance receptor model was used to estimate the source contribution, which requires source profile (source composition) data of plausible sources. The parameter 'wind velocity', in dispersion model has been optimized to get the concentration of the pollutant at the receptor equal to the receptor concentration data, which is the input of receptor model. The predictions using the two different methods can then be reconciled to accurately determine the wind velocity. The wind velocities predicted by the dispersion model are often found to be significantly different from those measured during the meteorological data collection. The proposed combined approach will reduce the concentration difference considering the information from the receptor and dispersion model approach. The algorithm demonstrated for distinct source profile contains five point sources and a receptor shown in figure 1.

Possible objective functions have been proposed to minimize error in the receptor concentrations predicted by the dispersion model, which is influenced by wind velocity and the experimentally measured concentrations (at receptor) for receptor model. The wind velocity at different source locations ' $U$ ' has been calculated, which minimize the difference between the experimental values of the receptor concentrations ' $R$ ' and that predicted from dispersion model. The first choice of objective function $\left(J_{1}\right)$ was to calculate the wind velocity ' $U$ ', such that 


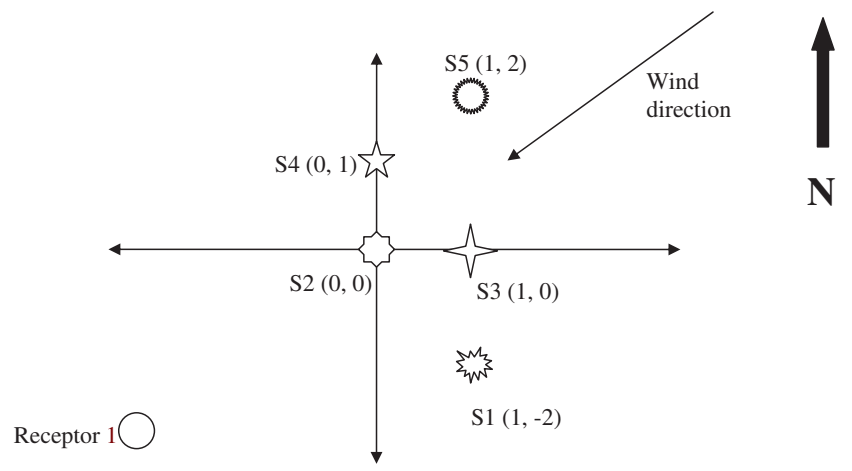

Figure 1. Location of five distinct point sources (S1, S2, S3, S4 and S5) relative to receptor location and wind direction.

the source contributions from dispersion model have to be in good agreement with that of the chemical mass balance receptor model, expressed in the following equation.

$$
\text { Minimize } U, J_{1}=\left\|S(U)_{(D i s)}-S_{C M B}\right\| \text {. }
$$

When the objective function contains the details of only the deviations in the predicted or experimental receptor concentrations or source contributions the optimization scheme may converge to different solutions depending on the initial guess. This can occur for instance, since the dependency on the wind velocity is linear. To attain a physically realistic solution the deviation of the velocity from the inventory estimates (location) is included in the objective function. This can lead to a unique confident solution to the optimization problem. The above objective function has been modified and expressed in the following equation.

$$
\text { Minimize } U, J_{2}=\left\|\mathrm{U}-\mathrm{U}_{\mathrm{est}}\right\|+\left\|\mathrm{S}(\mathrm{U})_{(\text {Dis })}-\mathrm{S}_{\mathrm{CMB}}\right\| \text {. }
$$

Here $S(U)_{D i s}$ and $S_{C M B}$ represent the source contribution from dispersion model (obtained through converged wind velocity as a parameter) and receptor model. The flow chart of the algorithm using the objective function ' $J_{2}$ ' has been given in figure 2 .

\subsection{Validation of the algorithm for distinct source profile}

The major assumption in the model was in the sense that all the five sources have unique or distinct source profiles (source composition). The current work illustrates the situation where all the emissions come from point sources were considered. The locations of these point sources were assumed to be known, as the wind conditions and other meteorological parameters. The concentration of pollutant at a point $(x, y, z)$ from a simple Gaussian plume model (Eq. 4) can be determined (Ghenai \& Lin 2009).

$$
C(x, y, z)=\frac{Q}{2 \pi \mathrm{U} \sigma_{y} \sigma_{z}}\left\{\exp \left(\frac{-\left(h_{R}-h_{S}\right)^{2}}{2 \sigma_{z}^{2}}\right)+\exp \left(\frac{-\left(h_{R}+h_{S}\right)^{2}}{2 \sigma_{z}^{2}}\right)\right\}\left[\exp \left(\frac{-(y)^{2}}{2 \sigma_{y}^{2}}\right)\right],
$$

where ' $Q$ ' is the emission rate $(\mathrm{kg} / \mathrm{s})$ from the point source, and ' $U$ ' is the mean wind velocity $(\mathrm{m} / \mathrm{s})$ at the point source. Here the downwind $(x)$ and cross wind $(y)$ distances are 


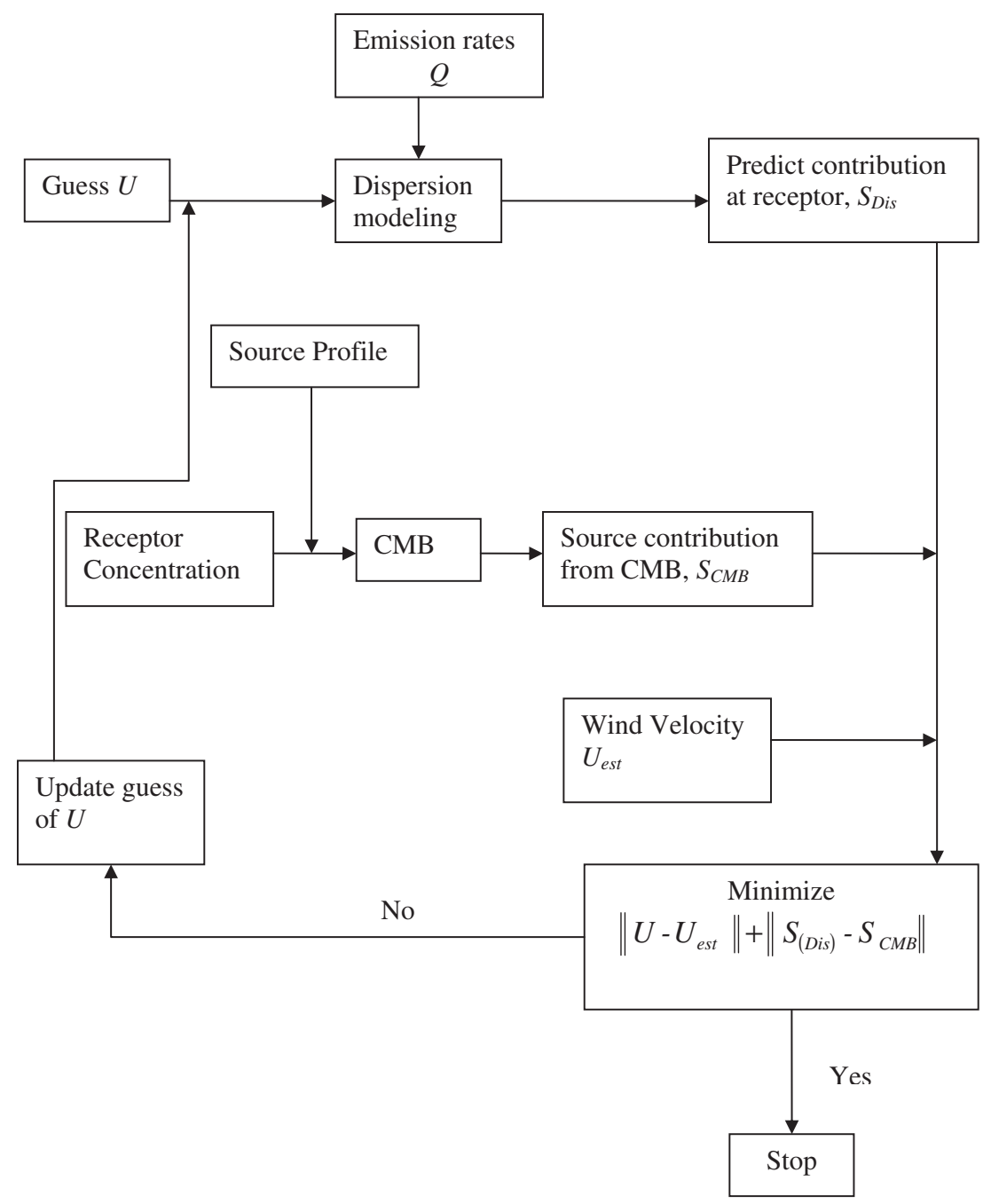

Figure 2. Validation of the proposed approach for source contribution using the objective function, $J_{2}$.

measured using Eq. 5a and Eq. 5b. ' $h_{R}$ ' and ' $h_{S}$ ' are the height $(\mathrm{m})$ of the receptor and stack respectively.

$$
\begin{gathered}
\mathrm{x}=(\mathrm{x}(\mathrm{r})-\mathrm{x}(\mathrm{s})) \operatorname{Sin}(\mathrm{wd}) \\
\mathrm{y}=(\mathrm{y}(\mathrm{r})-\mathrm{y}(\mathrm{s})) \operatorname{Cos}(\mathrm{wd}),
\end{gathered}
$$

where 'wd' is the wind direction, (r, s) is the coordinates of the location of respective point source.

The standard deviation in the horizontal direction has been calculated by the empirical correlation (Ghenai \& Lin 2009) as follows,

$$
\begin{gathered}
\sigma_{y}=465.11628(x) \tan (T H) \\
T H=0.017453293[c-d \ln (x)] .
\end{gathered}
$$


The standard deviation in the vertical direction has been obtained through the following empirical correlation,

$$
\sigma_{z}=a x^{b} .
$$

The parameters chosen for the evaluation of $\sigma_{y}, \sigma_{z}$ are $a=61.141, b=0.9146, c=12.5$ and $d=1.0857$.

Equation 4 illustrates the contributions of various sources and validation the methodology was illustrated for an ideal case. It was assumed that the source profile and wind velocities at the various source locations are known. The source contribution obtained $\left(S_{C M B}\right)$ from chemical mass balance $(\mathrm{CMB})$ has been used to solve the objective function ' $J_{2}$ '. Alternatively the experimental data were used to recover the source contributions compared. To illustrate the algorithm a straight forward approach was used and assumed that there is no uncertainty in the source profiles or in the experimental data set. The foundation of all receptor-based models for particle source assignment is a simple mass conservation argument. If a number of sources, ' $K$ ', exists, and if there is no reaction between the emitted pollutants that causes mass removal or formation, the total airborne particulate mass measured at the receptor, $C$, will be a linear sum of the contributions of the individual sources $S_{k}$.

$$
C=\sum_{k=1}^{K} S_{k} .
$$

Similarly, the mass concentration of $i^{\text {th }}$ species, $C_{i}$, will be

$$
C_{i}=\sum_{k=1}^{K} a_{i k} S_{k},
$$

where $a_{i k}$ is the mass fraction of $i^{\text {th }}$ species from $j^{\text {th }}$ source commonly known as the source profile or source signature. In general, Eq. 9 can be expressed as follows,

$$
S_{\mathrm{CMB}}=\left(P^{T} P\right)^{-1} P^{T} R
$$

where $P=$ Source profile (source composition, $\mu \mathrm{g} / \mu \mathrm{g}$ )

$R=$ Experimental concentration $\left(\mu \mathrm{g} / \mathrm{m}^{3}\right)$

$S_{\mathrm{CMB}}=$ Source contribution from chemical mass balance (CMB)

The algorithm demonstrated for distinct source profile contains five point sources and a receptor shown in figure 1. The location of these five point sources [S1, S2, S3, S4 and S5] has been considered in the coordinates $(1,-2),(0,0),(1,0),(0,1)$ and $(1,2)$ respectively. Calculated wind velocities can be obtained through primary wind velocities $\left(U_{e s t}\right)$, which serve as the initial guess in the algorithm. The base value or initial guess of $0.1,0.3,0.5,0.7$ and 0.9 has been respectively used to start the algorithm. The direction of the wind has been considered as $45^{\circ} \mathrm{NE}$ quarter of the receptor location $(-2,-2)$. The performance of objective function $J_{2}$ was analyzed for the above mentioned conditions. An initial guess of the wind velocities was assumed to start the algorithm. The optimization subroutine 'fminsearch' in MATLAB (R2008a) has been used to carry out the multivariable optimization scheme. To avoid the possibility of multiple solutions, $U-U_{\text {est }}$ term included in the objective function ' $J_{2}$ ' as explained earlier. 
Table 1. Error in Receptor concentration (R) in distinct Source profile for objective function, $J_{2}$.

\begin{tabular}{lcc}
\hline Variation in R (\%) & U converged & Error U \\
\hline \pm 0 & $0.2000,0.4000,0.6000,0.8000,1.0000$ & 0.0000 \\
\pm 10 & $0.2045,0.4002,0.6000,0.8101,1.0335$ & 0.1285 \\
\pm 40 & $0.1842,0.3286,0.6456,0.7553,0.9185$ & 0.1994 \\
\pm 60 & $0.2251,0.3546,0.5701,0.8047,0.8861$ & 0.1564 \\
\pm 80 & $0.1355,0.3088,0.2849,0.6254,1.0051$ & 0.2724 \\
\hline
\end{tabular}

$\mathrm{U}$ base value $=[0.1,0.3,0.5,0.7,0.9]$.

$\mathrm{U}$ estimate $=[0.2,0.4,0.6,0.8,1.0]$.

\section{Results and discussions}

The converged values of the wind velocity at five different locations with corresponding error variations in the receptor concentration have been given in table 1. It was observed that the error in receptor concentration variation increases, the error in the converged wind velocity at the five different locations also increased. The distinct source profile-receptor concentration error due to $20 \%$ and $80 \%$ variations in the wind velocities at five different locations for ten day analysis are shown in figure 3 and figure 4 respectively. It was observed that the deviation between the actual and average wind speed at different locations was very less except at the location 2 for $20 \%$ error in the wind speed. In figure 4 it was observed that the source profile-receptor concentration error increased as variation in wind velocity increased to $80 \%$. It was observed that the algorithm converge with the wind velocity used for generating the synthetic data set for different selection of initial guess ' $U$ '.

The emission rate $(Q)$ from a point source can be estimated and controlled in precise manner using the coupled-receptor dispersion model approach (Selvaraju \& Pushpavanam 2010), since both models predict the source contribution values at the receptor location $(R)$. The difference in the sense that dispersion model required the pollutant (Species) emission rate $(Q, \mathrm{~kg} / \mathrm{s})$,

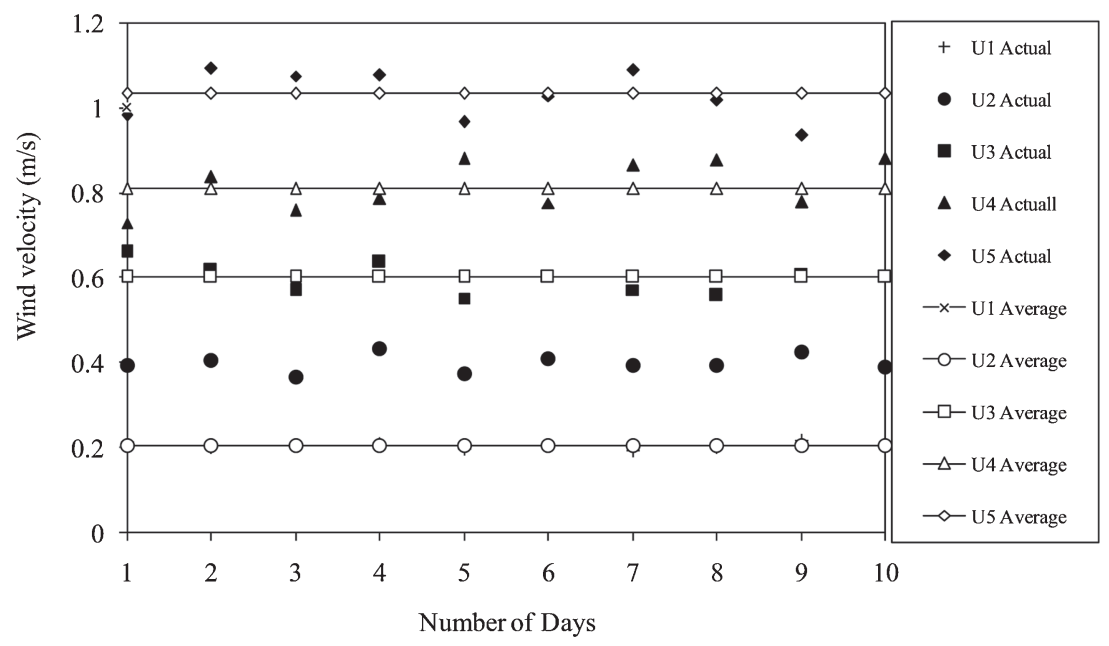

Figure 3. Distinct Source profile-receptor concentration-Error various $U \pm 20 \%$. 


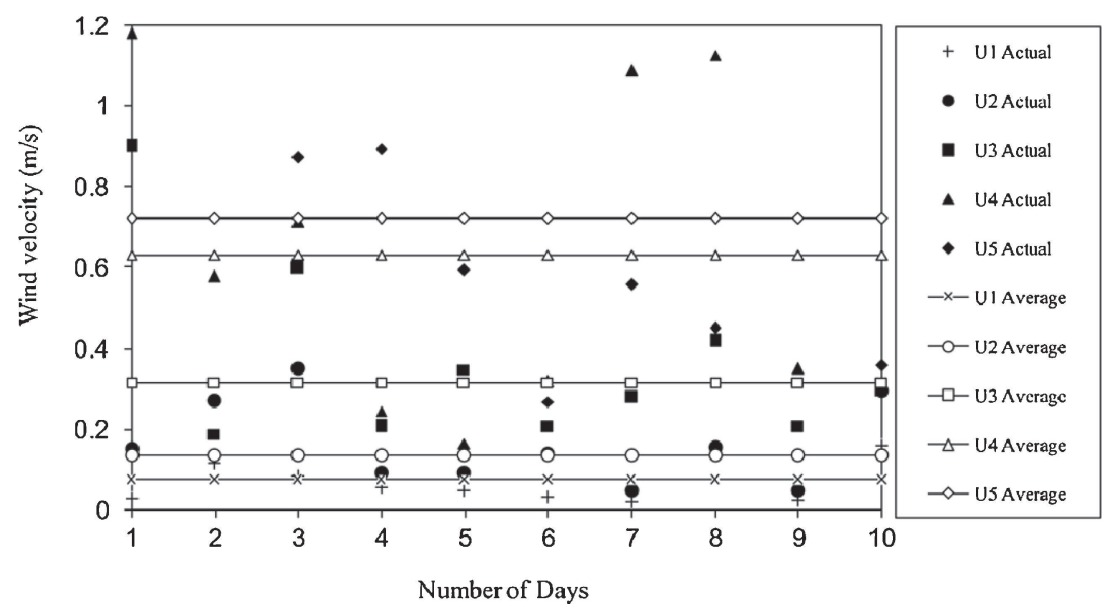

Figure 4. Distinct Source profile-receptor concentration-Error various $\mathrm{U} \pm 80 \%$.

source height $\left(h_{S}\right)$, receptor height $\left(h_{R}\right)$, downwind distance $(x)$, crosswind distance $(y)$, vertical height $(z)$, wind velocity $(u)$ and wind direction $(w d)$. Receptor model required the source profile (source signature), the receptor concentration data and their corresponding uncertainties (error in the measurement) to estimate the source contribution at the receptor location $(R)$ (Belis et al 2013).

\section{Conclusions}

In the current research work the information of wind velocity as well as receptor concentrations to achieve more accurate value of wind velocities through coupled receptor dispersion model has been discussed. Wind speed and direction contribute to pollution dispersion and which reflect the stability levels in the atmosphere. The possible objective functions were developed based on source contribution from receptor and dispersion models have been evaluated for only distinct source profiles case. Variation in the receptor concentrations leads the converged values of wind velocities with slight variations at the five locations and the corresponding error was increased. For example $10 \%$ and $80 \%$ error in R leads to the converged wind speed with error 0.1285 and 0.2724 respectively. The algorithm proposed helps to reconcile the differences between the predictions of the dispersion model and receptor model approaches. To resolve the mis-match in the results of receptor and dispersion model approach under steady state conditions and stability problems, the wind velocities are revised. It can be extended to cases where errors present in other variables such as other meteorological conditions. The methodology proposed here has been demonstrated on a synthetic data set. The first half of this work is based on assuming that the models and the data are perfect and uses a model-to-model comparison to illustrate the concept. It was then extended to the case when artificial errors were introduced to mimic measured data. The proposed approach can be effectively used for data obtained from a field study to find exact wind velocity for the stability of atmosphere.

Various meteorological parameters can be predicted accurately once the previous data available as input parameters to dispersion model, which will generate the receptor concentration and estimate the source contribution from theory behind the receptor model (CMB). Hence 
various possible errors in the newly generated parameter cause corresponding change the receptor concentration, which effectively influence in the $\mathrm{S}_{\mathrm{CMB}}$. So the newly proposed coupled receptor dispersion model provided accurate estimation of the wind velocity (dispersion model parameter) at the point source.

\section{Acknowledgement}

The authors are very grateful to the editors and reviewers valuable comments and suggestions made, which helped to improve the quality of the manuscript.

\section{References}

Barrett H S and Britter E R 2008 Development of algorithms and approximations for rapid operational air quality modelling. Atmos. Environ. 42: 8105-811

Barrett H S and Britter E R 2009 Algorithms and analytical solutions for rapidly approximating long-term dispersion from line and area sources. Atmos. Environ. 43: 3249-3258

Begum B A, Kim E, Biswas S K and Hopke P K 2004 Investigation of sources of atmospheric aerosol at urban and semi-urban areas in Bangladesh. Atmos Environ. 38: 3025-3038

Belis C A, Karagulian F, Larsen B R and Hopke P K 2013 Critical review and meta-analysis of ambient particulate matter source apportionment using receptor models in Europe. Atmos. Environ. 69: 94-108

Chowdhury Z, Zheng M, Schauer J J, Sheesley R J, Salmon L G, Cass G R and Russell A G 2007 Speciation of ambient fine organic carbon particles and source apportionment of $\mathrm{PM}_{2.5}$ in Indian cities. J. Geophys. Res. 112: D15303, 1-14

Fraser M P, Buzcu B, Yue Z W, Mcgaughey G R, Desai N R, Allen D T, Seila R L, Lonneman W L and Harley R A 2003 Separation of fine particulate matter emitted from gasoline and diesel vehicles using chemical mass balancing techniques. Environ. Sci. Technol. 37: 3904-3909

Ghenai C and Lin C X 2009 Dispersion modeling of $\mathrm{PM}_{10}$ released during decontamination activities. $J$. Hazard. Mater. 132: 58-67

Guo H, Ding A J, So K L, Ayoko G, Li Y S and Hung W T 2009 Receptor modeling of source apportionment of Hong Kong aerosols and the implication of urban and regional contribution. Atmos. Environ. 43: 1159-1169

Hanna S R, Chang J S and Strimaitis D G 1990 Uncertainties in source emission rate estimates using dispersion models. Atmos Environ. Part-A. General Topics. 24(12): 2971-2980

Hanna S, White J, Trolier J, Vernot R, Brown M, Gowardhan A, Kaplan H, Alexander Y, Moussafir J, Wang Y, Williamson C, Hannan J and Hendrick E 2011 Comparisons of JU2003 observations with four diagnostic urban wind flow and Lagrangian particle dispersion models. Atmos. Environ. 45(24): 40734081

Harrison R M, Smith D J T, Pio C A and Castro L M 1997 Receptor modelling study of airborne particulate pollutants in Birmingham (United Kingdom), Coimbra (Portugal) and Lahore (Pakistan). Atmos. Environ. 31(20): 3309-3321

Haupt S E 2005 A demonstration of coupled receptor/dispersion modeling with a genetic algorithm. Atmos. Environ. 39: 7181-7189

Held T, Chang P Y D and Niemeier A D 2003 UCD 2011: An improved model to simulate pollutant dispersion from roadways. Atmos. Environ. 37: 5325-5336

Henry R C, Lewis C W, Hopke P K and Williamson H J 1984 Review of receptor model fundamentals. Atmos. Environ. 18: 1507-1515

Holmes N S and Morawska L 2006 A review of dispersion modelling and its application to the dispersion of particles: An overview of different dispersion models available. Atmos. Environ. 40: 5902-5928

Hossain M A K and Easa S M 2012 Pollutant dispersion characteristics in Dhaka city, Bangladesh. AsiaPacific J. Atmos. Sci. 48(1): 35-41 
Kim H C and Lee H J 2012 Numerical simulations of Asian dust events: A Lagrangian Dust Model and its applications. Asia-Pacific J. Atmos. Sci. 49(5): 571-586

Lai C H, Chen K S, Ho Y T, Peng Y P and Chou Y M 2005 Receptor modeling of source contributions to atmospheric hydrocarbons in urban Kaohsiung, Taiwan. Atmos. Environ. 39: 4543-4559

Larsen R K and Baker J E 2003 Source apportionment of polycyclic aromatic hydrocarbons in the urban atmosphere: A comparison of three methods. Environ. Sci. Technol. 37: 1873-1881

Pant P and Harrison R M 2012 Critical review of receptor modelling for particulate matter: A case study of India. Atmos. Environ. 49: 1-12

Qian W and Venkatram A 2001 Performance of steady-state dispersion models under low wind-speed conditions. Bound-Lay, Meteorol. 138: 475-491

Seinfeld J H and Pandis S N 2006 Atmospheric chemistry and physics: From air pollution to climate change. John Wiley \& Sons, New York

Selvaraju N and Pushpavanam S 2010 Refining emission rate estimates using a coupled receptor-dispersion modeling approach. Atmos. Environ. 44: 3935-3941

Selvaraju N, Pushpavanam S and Anu N 2013 A holistic approach combining factor analysis, positive matrix factorization and chemical mass balance applied to receptor modeling. Environ. Monit. Assess. 185: $10115-10129$

Song Y, Zhang Y, Xie S, Zeng L, Zheng M, Salmon L G, Shao M and Slanina S 2006 Source apportionment of $\mathrm{PM}_{2.5}$ in Beijing by positive matrix factorization. Atmos. Environ. 40: 1526-1537

Stone E, Schauer J, Quraishi T A and Mahmood A 2010 Chemical characterization and source apportionment of fine and coarse particulate matter in Lahore, Pakistan. Atmos. Environ. 44: 1062-1070

Stull R and Ainslie B 2006 A simple model for pollution dispersion in a convective boundary layer. J. Appl. Meteorol. 45: 1727-1743

Tsai Y I and Chen C L 2006 Atmospheric aerosol composition and source apportionments to aerosol in southern Taiwan. Atmos. Environ. 40: 4751-4763

Vinod K A, Patil R S and Nambi K S V 2001 Source apportionment of suspended particulate matter at two traffic junctions in Mumbai, India. Atmos. Environ. 35: 4245-4251

Warner T T, Sheu R S, Bowers J F, Sykes R I, Dodd G C and Henn D S 2002 Ensemble simulations with coupled atmospheric dynamic and dispersion models: illustrating uncertainties in dosage simulations. $J$. Appl. Meteorol. 41: 488-504 